\title{
Histopathology of Pancreatic Solid Pseudo-papillary Neoplasm Failed to Predict Metastatic Potential: A Case Report of 2 Cases from a Tertiary Care Centre
}

\author{
Anuradha Sekaran ${ }^{1}$, Abid Hussain ${ }^{1}$, Partha $\mathrm{Pal}^{2}$, Duvuru Nageshwara Reddy ${ }^{2}$ \\ Departments of ${ }^{1}$ Pathology and ${ }^{2}$ Medical Gastroenterology, Asian Institute of Gastroenterology, Hyderabad, Telangana, India.
}

\section{Corresponding Author:}

Dr Abid Hussain

Email: hussain.abid111@gmail.com

This is an Open Access article distributed under the terms of the Creative Commons Attribution License (creativecommons.org/ licenses/by/3.0).

Received Accepted

Published

May 5, 2018

October 23, 2018

November 5, 2018

\begin{abstract}
Background: Solid pseudo-papillary neoplasm (SPN) of the pancreas is a rare cystic tumor of pancreas which usually affects young females. Most patients remain asymptomatic for many years prior to diagnosis. Moreover, only rarely, the disease can be locally advanced or metastatic at presentation. Case Report: We report our experience with two cases of SPN of the pancreas with metastasis to liver and peritoneum at the time of presentation. Both were young females who presented with intermittent abdominal pain. Tumor's size ranged from $6.3-7 \mathrm{~cm}$ in greatest dimension. One case was diagnosed pre-operatively through percutaneous core needle biopsy and the other case had a fine needle aspiration done and later underwent surgery because of high suspicion of SPN based on clinical and radiological findings. By immuno-histochemistry, all cases stained strongly positive for pancytokeratin, vimentin, CD10, beta-catenin (nuclear) and neuroendocrine markers (synaptophysin). However, they were negative for chromogranin and CA19.9. Though these cases showed metastasis, the proliferation index (Ki-67) was very low $<3 \%$ in both the cases. Conclusion: SPN of the pancreas should be considered in the differential diagnosis of any solid and partly cystic pancreatic or upper abdominal mass, particularly in young females. Histopathological features of metastatic potential of SPN have been predicted by several factors however they could not predict metastasis in our cases.
\end{abstract}

Keywords: Abdominal Pain, Fine Needle Biopsy, Immunohistochemistry, Pancreas, Pancreatic Neoplasms, Peritoneum, Vimentin.

\section{Introduction}

Solid pseudo-papillary neoplasm (SPN) of the pancreas is a rare tumor accounting for 1 to $2 \%$ of all exocrine pancreatic tumors which typically affects young women (90\%). SPN was initially recognized as Guber-Frantz's tumor as it was first described by Frantz Virginia [1] in 1959 as "papillary cystic tumor of the pancreas". Other names are solid cystic pancreatic neoplasm, papillary epithelial neoplasm of pancreas of childhood and solid pseudo-papillary neoplasm. SPN is a low-grade malignant neoplasm [2] with an indolent behavior and only rare cases recur and/ or metastasize after complete resection. Metastasis is seen in $5-10 \%$ cases. There are many large series of SPN from various countries [3]. However case reports on metastasis of SPN are very few [4]. We report our experience with two cases of pancreatic SPN with metastasis to liver and peritoneum.

\section{Case Reports}

\section{Case 1}

A 29-year-old female presented to the hospital with complains of intermittent episodes of pain abdomen for last one year. On computed tomography (CT), there was a heterogenous solid to cystic mass measuring $7 \times 6 \times 5 \mathrm{cms}$ in the body and tail of pancreas with multiple peritoneal nodules suggesting possibility of peritoneal metastasis. FNAC from pancreas showed features of SPN. The patient underwent distal pancreatectomy, splenectomy and metastatectomy. 
Gross examination revealed a cystic irregular mass measuring $7 \times 6 \times 5 \mathrm{cms}$. Cut surface was partly solid and partly cystic. The resected margins of surgical specimen appeared uninvolved by the tumor. On microscopic examination, the tumor was partially encapsulated. Solid areas showed cells predominately arranged in pseudopapillary pattern, sheets, nodules and islands separated by thin fibrovascular septae. Cells were monomorphic round, with round to oval nucleus, granular chromatin with prominent nuclear grooves and moderate amount of eosinophilic cytoplasm with intra and extracellular hyaline globules. Cystic areas showed spaces lined by flattened to cuboidal cells. Aggregates of foamy macrophages, cholesterol clefts were seen. Areas with marked hemorrhage, necrosis and hyalinization were noted [Fig.1]. The resected margins and lymph nodes were free of tumor. Immunohistochemistry performed showed strong positivity for pancytokeratin, vimentin, nonspecific esterase (NSE), CD 10. Strong nuclear positivity was seen for beta-catenin [Fig.2]. Ki67 labelling index was 2\%. The tumor cells were negative for chromogranin and CA19.9. The microscopic findings of the peritoneal nodule were similar to the findings of the pancreatic tumor with similar IHC pattern and low Ki 67 $(3 \%)$. Microscopic examination of spleen showed congestive splenomegaly. A final diagnosis of SPN of the pancreas with peritoneal metastasis was made.

\section{Case 2}

A 13-year-old female presented with complains of pain abdomen and vomiting since two months. On esophagogastro-duodenoscopy (EGD), there was an extrinsic bulge in the antrum and duodenum. CT abdomen showed a large heterogenous mass lesion measuring $6.3 \times 3.7 \times 3 \mathrm{cms}$ in the head and neck of pancreas with multiple heterogenous mass lesions seen in both lobes of liver [Fig.3].

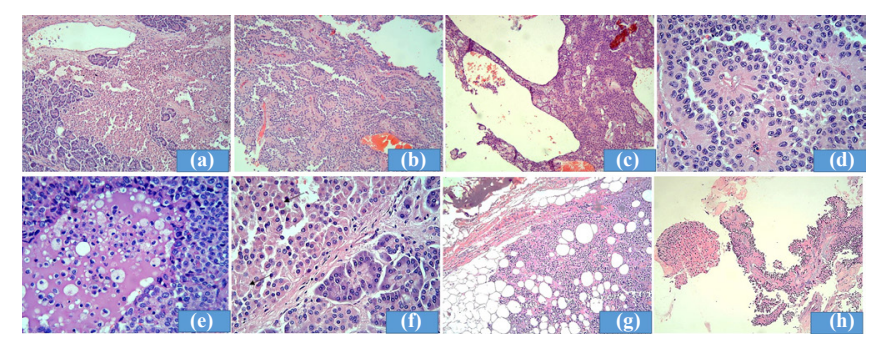

Fig.1: Histopathological examination with H\&E stains displaying (a): tumor infiltrating the adjacent normal pancreas $(\times 100)$, (b): pseudopapillary pattern and $(\times 100)$ (c): cystic pattern of arrangement of tumor cells $(\times 100)$, (d): pseudopapillary pattern with tumor cells surrounding the hyalinised fibrovascular core and cells are polyhedral with abundant cytoplasm and oval nuclei with prominent nuclear grooves $(\times 400)$, (e): cystic areas filled with cystic fluid and cyst macrophages (×400), (f): Oncocytic cells with cytoplasmic globules; at places there is disruption of cytoplasm with extracellular release of hyaline globules (arrow) (×400), (g): peritoneal nodule infiltration by cells arranged in sheets $(\times 100)$, (h): Liver biopsy with hepatocytes infiltrated by tumor with psudopapillary architecture $(\times 100)$.

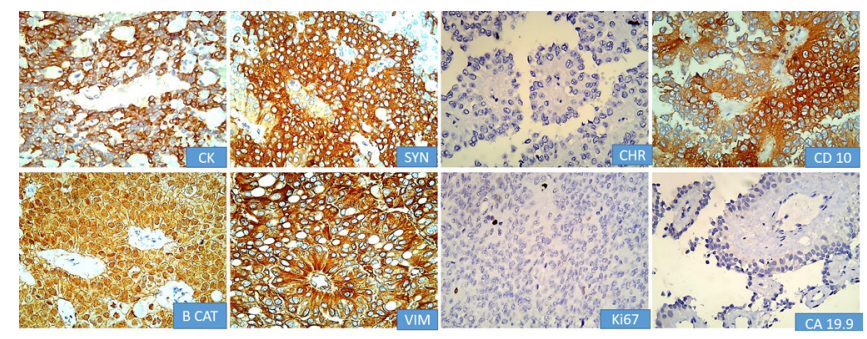

Fig.2: Immunohistochemistry performed with (a): pancytokeratin. (b): synaptophysin, (c): chromogranin, (d): CD10, (e): Beta Catenin, (f): Vimentin, (g): Ki 67, (h): $C A 19.9$.

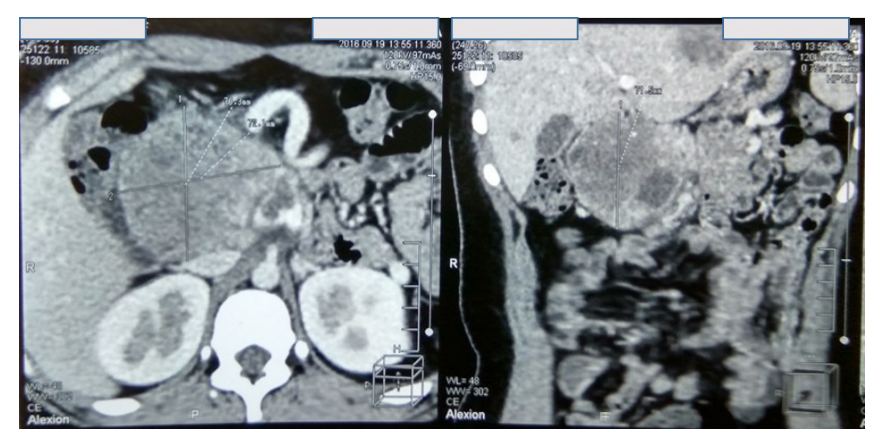

Fig.3: CT abdomen showing a large heterogenous mass lesion measuring $6.3 \times 3.7 \times 3 \mathrm{cms}$ in the head and neck of pancreas with multiple heterogenous mass lesions seen in both lobes of liver. 
Table 1: Clinicopathological and radiological findings of the two cases.

\begin{tabular}{|l|l|l|l|l|l|l|l|}
\hline Case no. & Age / Sex & $\begin{array}{l}\text { Presenting } \\
\text { complaint }\end{array}$ & $\begin{array}{l}\text { Site of pancreatic } \\
\text { lesion }\end{array}$ & Size of lesion & Site of metastasis & $\begin{array}{l}\text { Radiological } \\
\text { findings }\end{array}$ & $\begin{array}{l}\text { Final } \\
\text { histopathological } \\
\text { diagnosis }\end{array}$ \\
\hline Case 1 & $29 / \mathrm{F}$ & $\begin{array}{l}\text { Pain abdomen, } \\
\text { vomiting, } \\
\text { anemia }\end{array}$ & Body and tail & $7 \times 6 \mathrm{cms}$ & $\begin{array}{l}\text { Multiple } \\
\text { peritoneal nodules }\end{array}$ & $\begin{array}{l}\text { Heterogenous } \\
\text { mass lesion with } \\
\text { tiny calcifications }\end{array}$ & $\begin{array}{l}\text { SPN with } \\
\text { peritoneal } \\
\text { metastasis }\end{array}$ \\
\hline Case 2 & 13 / F & Pain abdomen & Head and neck & $6.3 \times 3.7 \times 3 \mathrm{cms}$ & $\begin{array}{l}\text { Multiple lesions } \\
\text { in liver }\end{array}$ & $\begin{array}{l}\text { Heterogenous } \\
\text { mass lesion }\end{array}$ & $\begin{array}{l}\text { SPN with liver } \\
\text { metastasis }\end{array}$ \\
\hline
\end{tabular}

Biopsies from pancreas and liver showed similar morphology and IHC pattern of staining as described above in case one. Ki 67 labelling index was $3 \%$ in both liver and pancreas. A final diagnosis of SPN of the pancreas with liver metastasis was made. She was not operated because she was found to be inoperable and R0 resection was not possible. Chemotherapy was not given as there is no proven role of chemotherapy in SPN.

\section{Discussion}

SPN accounts for less than $10 \%$ of cystic neoplasms of pancreas and occurs mostly in females (female: male: 10:1). Most cases occur in young female in third decade although older age of onset $(>50$ years: $5 \%$ cases) and pediatric onset has been described (1-18 years: $20 \%)$.

Most common clinical presentation are abdominal pain (67-81\%) and abdominal mass $(35 \%)$. A significant proportion of the cases are diagnosed incidentally (15\%). Most cases involve body and tail (60\%) with size larger than $10 \mathrm{~cm}$. Similar location was found in our cases and the tumors were of 6.3-7 $\mathrm{cm}$ in diameter [Table 1]. The close differential of SPN on histopathology is neuroendocrine tumor which can be differentiated by demonstration of CD 10 and Beta-catenin in SPN [Table 2].

Recurrence after curative resection occurs in $10-15 \%$ of cases. Mao et al. reviewed 292 patients with SPN, of these $14.7 \%$ (43 of 292) were diagnosed as malignant due to metastasis $(22$ of hepatic, lymph node metastasis or peritoneal
Table 2: Histopathological findings and immunohistochemistry panel of both the cases.

\begin{tabular}{|c|c|c|}
\hline $\begin{array}{l}\text { Histopathological } \\
\text { Findings }\end{array}$ & Case 1 & Case 2 \\
\hline Pseudo-papillary pattern & + & + \\
\hline Nuclear grooves & + & - \\
\hline $\begin{array}{l}\text { Eosinophilic hyaline } \\
\text { globules }\end{array}$ & + & - \\
\hline Necrosis & + & + \\
\hline Hyalinization & + & + \\
\hline Cholesterol clefts & + & - \\
\hline Foamy macrophages & + & + \\
\hline Immuno-histochemistry & & \\
\hline Pan cytokeratin & Focal + & + \\
\hline Synaptophysin & + & + \\
\hline Chromogranin & - & - \\
\hline CD 10 & + & + \\
\hline Beta-catenin & Nuclear + & Nuclear + \\
\hline Vimentin & + & + \\
\hline Ki 67 & $2 \%$ & $2 \%$ \\
\hline CA 19.9 & - & - \\
\hline
\end{tabular}

dissemination) or invasion into adjacent organs. Metastasis develops in less than $10 \%$ with metastasis to liver being most common. Curative resection for hepatic metastasis is possible if involvement is limited. However, Martin et al. [5] suggested that complete resection was associated with long-term survival even in the presence of metastatic disease. In many case report series, even patients with local recurrence as well as liver and peritoneal metastasis have experienced long-term survival after surgical resection [6,7]. Similarly with one of our case, as there were multiple liver metastasis, surgery with resection of liver was advised. However 
Table 3: Comparison of several studies predicting clinico-pathological features associated with metastatic SPN.

\begin{tabular}{|c|c|c|c|c|}
\hline $\begin{array}{l}\text { Features predicting } \\
\text { malignant SPN }\end{array}$ & Nishihara et $\mathrm{al}^{8}$ & Klimstra et $a l^{9}$ & Woo Seok Nam, et al ${ }^{10}$ & Present study \\
\hline Age (elderly, $>50$ years) & - & Elderly, $>50$ years & - & $\begin{array}{l}\text { Young adults } \\
\text { ( } 29 \text { and } 13 \text { years) }\end{array}$ \\
\hline Tumor size $(>10 \mathrm{cms})$ & - & $>10 \mathrm{cms}$ & $>10$ years & $<10 \mathrm{cms}$ \\
\hline $\begin{array}{l}\text { Cellular/nuclear } \\
\text { pleomorphism }\end{array}$ & High grade & High grade & No pleomorphism & No pleomorphism \\
\hline Mitosis & - & Increased & Low $(<5 \%)$ & Low $(3 \%)$ \\
\hline Necrosis & Present & - & - & Absent \\
\hline Lymphovascular invasion & Present & Present & - & No \\
\hline Perineural invasion & - & Present & Present & No \\
\hline
\end{tabular}

the patient refused for surgery. There are several studies showing microscopic features predicting metastatic potential in malignant SPN [Table 3].

The prognosis for SPN is excellent after curative resection in non-metastatic SPN (more than $90 \%$ survival at 5 years). Metastatic SPN are frequently amenable to resection. Favorable prognosis with long term survival has been shown in patients with metastasis [8]. Similarly prognosis was good in one of our case (with peritoneal metastasis) after surgical resection of peritoneal nodule, with $100 \%$ survival rate after one year of follow-up.

\section{Conclusion}

Though SPN possesses a low malignant potential it can rarely metastasize to adjacent sites and should be considered in the differential diagnosis of suspected metastatic pancreatic lesions. Histopathological features of metastatic potential of SPN have been predicted by several studies however they could not predict metastasis in our cases. Pre-operative diagnostic work-up is a cornerstone for surgical approach and complete surgical resection with clear margins is the treatment of choice even after metastasis.

Contributors: AS: drafting of manuscript, analysis and technical support and supervision; AH: clinical history, manuscript drafting; PP: clinical history and management, critical inputs into the manuscript; DNR: patient management and manuscript editing. AH will act as guarantor of the study. All authors approved the final version of this manuscript.

Funding: None; Competing interests: None stated.

\section{References}

1. Frantz VK. Tumors of the pancreas. In: Bumberg CW, editors. Atlas of Tumor Pathology, VII. Fascicles 27 and 28. Washington, DC: Armed Forced Institute of Pathology; 1959. pp. 32-33.

2. Klöppel G, Hruban RH, Klimstra DS, Maitra A, Morohoshi T, Notohara K, et al. Solid-pseudopapillary neoplasm of pancreas. In: Bosman FT, Carneiro F, Hruban RH, Theise ND, editors. World Health Organization Classification of Tumors of the Digestive System. Lyon: IARC; 2010. pp. 327-330.

3. Patil T, Shrikhande S, Kanhere H, Saoji R, Ramadwar M, Shukla P. Solid pseudopapillary neoplasm of the pancreas: a single institution experience of 14 cases. HPB (Oxford). 2006;8:148-150.

4. Vassos N, Agaimy A, Klein P, Hohenberger W, Croner RS. Solid-pseudo-papillary neoplasm (SPN) of the pancreas: case series and literature review on an enigmatic entity. International Journal of Clinical and Experimental Pathology. 2013;6:1051-1059.

5. Martin RC, Klimstra DS, Brennan MF, Conlon KC. Solid-pseudopapillary tumor of the pancreas: a surgical enigma? Ann Surg Oncol. 2002;9:35-40.

6. Horisawa $\mathrm{M}$, Niinomi $\mathrm{N}$, Sato $\mathrm{T}$, Yokoi $\mathrm{S}$, Oda $\mathrm{K}$, Ichikawa M, et al. Frantz's tumor (solid and cystic tumor of the pancreas) with liver metastasis: successful treatment and long-term follow-up. J Pediatr Surg. 1995;30:724-726.

7. Lee HS, Kim HK, Shin BK, Choi JH, Choi YJ, Kim HY. A rare case of recurrent metastatic solid pseudopapillary 
neoplasm of the pancreas. Journal of Pathology and Translational Medicine. 2017;51:87-91.

8. Nishihara K, Nagoshi M, Tsuneyoshi M, Yamaguchi K, Hayashi I. Papillary cystic tumors of the pancreas. Assessment of their malignant potential. Cancer. 1993;71:82-92.

9. Klimstra DS, Wenig BM, Heffess CS. Solid- pseudopapillary tumor of the pancreas: a typically cystic carcinoma of low malignant potential. Semin Diagn Pathol. 2000;17:66-80.

10. Woo Seok Nam, Yong Sung Won, Dong Do You, Jin Mo Yang, Jee Han Jung, et al. solid pseudopapillary tumor with hepatic metastasis: A case report. J Korean Surg Soc. 2011;81:S55-58. 